Review

\title{
Heat Shock Protein 90 (Hsp90) Expression and Breast Cancer
}

Flora Zagouri *, Evangelos Bournakis, Konstantinos Koutsoukos and Christos A. Papadimitriou

Department of Clinical Therapeutics, Alexandra Hospital, School of Medicine, University of Athens, 80 Vas. Sofias Ave, 11528 Athens, Greece; E-Mails: vagimith@yahoo.com (E.B.);

kkoutsoukos@yahoo.gr (K.K.); chr_papadim@yahoo.gr (C.A.P.)

* Author to whom correspondence should be addressed; E-Mail: florazagouri@yahoo.co.uk;

Tel.: +30-694-646-2998; Fax: +30-210-338-1511.

Received: 19 July 2012; in revised form: 30 August 2012 / Accepted: 10 September 2012 /

Published: 12 September 2012

\begin{abstract}
Hsp90 is an abundant protein in mammalian cells. It forms several discrete complexes, each containing distinct groups of co-chaperones that assist protein folding and refolding during stress, protein transport and degradation. It interacts with a variety of proteins that play key roles in breast neoplasia including estrogen receptors, tumor suppressor p53 protein, angiogenesis transcription factor HIF-1alpha, antiapoptotic kinase Akt, Raf-1 MAP kinase and a variety of receptor tyrosine kinases of the erbB family. Elevated Hsp90 expression has been documented in breast ductal carcinomas contributing to the proliferative activity of breast cancer cells; whilst a significantly decreased Hsp90 expression has been shown in infiltrative lobular carcinomas and lobular neoplasia. Hsp90 overexpression has been proposed as a component of a mechanism through which breast cancer cells become resistant to various stress stimuli. Therefore, pharmacological inhibition of HSPs can provide therapeutic opportunities in the field of cancer treatment. 17-allylamino,17-demethoxygeldanamycin is the first Hsp90 inhibitor that has clinically been investigated in phase II trial, yielding promising results in patients with HER2-overexpressing metastatic breast cancer, whilst other Hsp90 inhibitors (retaspimycin HCL, NVP-AUY922, NVP-BEP800, CNF2024/BIIB021, SNX-5422, STA-9090, etc.) are currently under evaluation.
\end{abstract}

Keywords: hsp90; breast cancer; 17-allylamino-17-demethoxygeldanamycin 


\section{Introduction}

Heat shock proteins (HSP) are members of the molecular chaperones, a group of proteins that play essential role in the folding of a large number of cellular proteins [1,2]. They were firstly discovered as mediators of resistance to hyperthermia [3]. Moreover, they participate directly in cell survival during hyperthermia by inhibiting programmed cell death and cell senescence [4-7]. HSPs appear to be utilized in carcinogenesis in order for cells to escape the pathways of tumour suppression, to promote progression in more advanced stage, to become treatment-resistant, and to facilitate metastasis [8].

The transcription of HSP genes is regulated by transcription factor HSF1; the latter senses cellular exposure to stress and turns on rapid induction of HSPs $[9,10]$. Moreover, HSF1 plays a putative role in breast carcinoma progression by inducing HSPs [11]. Additionally, HSF1 includes activation of metastasis by the silencing of anti-metastatic processes, activates pro-malignant signalling cascades and regulates the mitotic spindle checkpoint [12-14]. Hsp27 and Hsp70 appear to foster carcinogenesis by inhibiting apoptosis and senescence [8]. Mitochondria possess a subclass of HSPs including the Hsp70 homolog mortalin and TRAP-1 as well as Hsp60; all of them playing a key role in cancer progression $[15,16]$.

Hsp90 is an abundant protein in mammalian cells [17]. It forms several discrete complexes, each containing distinct groups of co-chaperones that assist protein folding and refolding during stress, protein transport and degradation [18]. Hsp90 interacts with a variety of proteins that play key roles in breast neoplasia; including estrogen receptors (ER), tumor suppressor p53 protein, angiogenesis transcription factor HIF-1alpha, antiapoptotic kinase Akt, Raf-1 MAP kinase and a variety of receptor tyrosine kinases, such as HER2 (reviewed in [19]). This review article summarises the more significant points supporting the role of Hsp90 in breast carcinoma.

\section{Hsp90 Biology}

Hsp90 is highly conserved and expressed in a variety of different organisms from bacteria to mammals - including the prokaryotic analogue HtpG (high temperature protein G) with 40\% sequence identity and 55\% similarity to the human protein [20] Yeast Hsp90 is 60\% identical to human Hsp90 $\alpha$.

In mammalian cells, there are two or more genes encoding cytosolic Hsp90 homologues [20], with the human Hsp90 $\alpha$ showing $85 \%$ sequence identity to Hsp90 [21]. The $\alpha$ - and the $\beta$-forms are thought to be the result of a gene duplication event that occurred millions of years ago [20]. A membrane-associated variant of cytosolic Hsp90, lacking an ATP-binding site, has recently been identified and was named Hsp90N [22]. This HSP90 $\alpha-\Delta-N$ transcript is a chimera, with the first 105 bp of the coding sequence derived from the CD47 gene on chromosome 3q13.2, and the remaining coding sequence derived from HSP90AA1 [21]. However, gene-encoding Hsp90N was later proven to be non-existent in human genome. It is possibly a cloning artifact or a product of chromosomal rearrangement occurring in a single cell line [23].

Hsp90 consists of four structural domains [24-26]:

(1). A highly conserved $N$-terminal domain (NTD) of $\sim 25 \mathrm{kDa}$

(2). A "charged linker" region, that connects the $N$-terminus with the middle domain

(3). A middle domain (MD) of $\sim 40 \mathrm{kDa}$

(4). A $C$-terminal domain (CTD) of $\sim 12 \mathrm{kDa}$. 
The $\mathrm{NH}_{2}$-terminal domain consists of a highly twisted eight-stranded $\beta$ sheet exposed to solvent on one side, whereas the other side is covered by helices that pack to form a pocket, which is the ATP-binding site [27]. Crystal structures are available for the $N$-terminal domain of yeast and human Hsp90 [27-29], for complexes of the $N$-terminus with inhibitors and nucleotides [27,28] and for the middle domain of yeast Hsp90 [30]. Recently structures for full length Hsp90 from E. coli (2IOP, 2IOQ) [31] yeast (2CG9, 2CGE) [32] and the dog endoplasmic reticulum (2O1U, 2O1V) [33] were elucidated [34]. Hsp90 forms homodimers where the contact sites are localized within the $C$-terminus in the open conformation of the dimer. The $N$-termini also come in contact in the closed conformation of the dimer [30].

HSP90 functions as a part of a multi-chaperone complex, involving the dynamic association with various accessory co-chaperones and client proteins [35]. In an ATP-bound state, HSP90 adopts a closed conformation and becomes a mature complex that is essential for it to perform its function of client protein folding and stabilization [35]. The chaperone cycle involves a complex series of loading and unloading events, which require a host of co-chaperones, such as HSP70, HSP40, HOP, AHA1, and p23 [36]. As already mentioned, HSP90 plays a putative role to the stability and function of a host of proteins such as BCR-ABL, HER2, epidermal growth factor receptor (EGFR), CRAF, BRAF, AKT, MET, VEGFR, FLT3, androgen and estrogen receptors, hypoxia-inducible factor (HIF)-1a, and telomerase; these protein play key roles in breast neoplasia such as growth factor independence, resistance to antigrowth signals, unlimited replicative potential, tissue invasion and metastasis, avoidance of apoptosis, and sustained angiogenesis [35,36]. Therefore, it is obvious why HSP90 should be considered an important molecular target for breast cancer.

All the HSP90 inhibitors in clinical development to date are focused on the ATP binding site of the $\mathrm{N}$-domain [37]. Recent efforts have been directed to towards alternative approaches such as inhibition of the $C$-terminus [38], or inhibition of co-chaperones such as CDC37 [39], AHA 1 [40], HSP27 [41], HSP70 and HSF-1 [42].

In this point it should be underlined that inhibiting HSP90, multiple signal transduction pathways are combinatorial inhibited. HSP90 inhibitors are thought to be cytostatic agents and one way to increase their efficacy and to realize their full therapeutic potential would to use combinatorial approaches. For example because HSP90 inhibitors can lead to simultaneous disruption of many signal transduction pathways and therefore deliver a combinatorial effect through a single molecular target (HSP90); they can be combined with other biologic/targeted agents and thus prevent or reverse the resistance of these targeted agents [43]. Similarly, preclinical models have suggested additive/synergistic effects when HSP90 inhibitors are combined with conventional chemotherapy or radiotherapy [37,43].

\section{Hsp90 Expression in Breast Carcinogenesis}

Elevated Hsp90 expression has been documented in breast ductal carcinomas [44-48], whilst a significantly decreased Hsp90 expression has been shown in infiltrative lobular carcinomas and lobular neoplasia $[49,50]$.

The persistent downregulation of Hsp90 expression throughout the whole lobular series (at the precursor and invasive components) may be contrary to what might have been expected; it is known that Hsp90 overexpression is a feature of invasive ductal carcinomas [45-47,51,52]. It is thus tempting 
to speculate that the whole lobular series may display a discrete, less intense profile of Hsp90 expression, which differentiates itself from the marked upregulation in ductal carcinomas. The underlying mechanisms of this discrepancy remain elusive.

According to our published results [48], ductal hyperplasia without atypia, atypical ductal hyperplasia (ADH) and ductal carcinoma in situ (DCIS) do not exhibit marked Hsp90 upregulation, while IDC presents with high Hsp90 expression. This finding may imply that the precursor context may not entail the cellular stress present in invasive cancer [50]. Consequently, as an integral part of the stress response, Hsp90 per se appears not to have been triggered early [48]. Within IDC, a higher grade, larger tumor size, higher ER expression and HER2 positivity correlate with higher Hsp90 expression [48]. More specifically, tumors of larger size also presented with more pronounced Hsp90 upregulation $[47,48]$ which seems to reflect the stress-related events in rapidly proliferating hypoxic (due to their size) tumors. Significantly decreased Hsp90 expression has been observed in triple-negative tumours $[48,53]$. This may seem fairly rational as Hsp90 is associated with ER and HER2 expression. However, this observation highlights a paradox; on the one hand elevated Hsp90 has been suggested as a poor prognostic factor [53], whilst on the other hand triple-negative tumors, exhibiting decreased Hsp90 expression, are associated with poor prognosis (reviewed in [54]).

The discrepancy between HSP90 expression in IDC and ILC is rather very interesting. A high HSP90 expression in primary breast cancer has been described as a poor prognostic marker in breast cancer [47]. HSP90 expression was variable in patient tumors compared to cancer cell lines. Whether this expression is also variable between primary and metastatic tumors is unknown at this time. It is important to note that HSP90 inhibitors have been used in breast cancer only in the metastatic and refractory settings. Additionally, studies have not described HSP90 expression as a marker that can predict response to HSP90 inhibitor therapy. At the Annual ASCO meeting in June 2012 [55], a small recent retrospective study evaluated pre-treatment tumor specimens for biomarkers such as HSP90 and HSP70 expression and other client proteins (using immunohistochemical staining) that can predict response to HSP90 inhibitors. The sample size was too small to make any definitive conclusions; however, the most important predictive biomarker was HER2. HSP90 expression did not correlate strongly with response [55]. Prospective studies are ultimately needed to further elucidate the role of HSP90 expression and other predictive biomarkers of response to HSP90 inhibitor therapy.

Contrary to the pathological findings published by our team [48-50], as well as by other research groups [45-47,51], according to which Hsp90 exhibits significant variability along both series, such a finding was not replicated at the level of Hsp90 serum concentrations [56].

\section{Hsp90 Inhibitors and Breast Cancer}

Breast cancer is an indication where HSP90 inhibitors should be explored for a variety of reasons (reviewed in [35]). Firstly, inhibition of HSP90 degrades HER2, a client protein, and HSP90 inhibitors have shown activity in HER2-driven xenograft models [57]. Moreover, modulation of estrogen and progesterone receptor signaling has been a long-standing approach to treating breast cancer and both estrogen and progesterone receptors are clients of HSP90 [58]. Additionally, resistance of breast cancer cells to chemotherapy is known to involve the phosphatidylinositol 3-kinase pathway [59], which is modulated by HSP90 by virtue of one of its key signaling proteins (AKT) being a client 
protein of HSP90. Furthermore, inhibition of HSP90 has also been known to modulate angiogenesis of breast cancer xenografts [60]. Finally, expression of HSP90 has been shown to correlate with adverse clinical outcomes, further validating HSP90 as a target in breast cancer [47]. Given the above observation, it would appear that pharmacological inhibition of Hsps can provide therapeutic opportunities in the field of cancer treatment [61]; Hsp90 inhibitors include the natural products geldanamycin and radicicol as well as semisynthetic derivatives 17- $N$-Allylamino-17-demethoxygeldanamycin (17AAG) [62].

Geldanamycin, bind directly to the ATP-binding pocket in the $N$-terminal domain of Hsp90, blocks the binding of nucleotides to Hsp90. Geldanamycin causes the degradation of the steroid receptor, blocking the chaperone cycle at the intermediate complex, and preventing the release of the receptor from the Hsp90-complex [63]. Radicicol-based inhibitors have not entered clinical development.

17-N-Allylamino-17-demethoxygeldanamycin (17AAG) is the semi-synthetic derivative of Geldanamycin, exhibiting a less toxic profile, but with same therapeutic potential as Geldanamycin. It is the first HSP90 inhibitor that has been tested in clinical trials. The aforementioned agent decreases the concentration of client proteins and deregulates the client proteins like hsc, keratin 8 , keratin 18 , akt, c-rafl and caveolin-1, resulting in inhibition of signal transduction [64].

The development of isoform-selective drugs that are targeted to particular members of the HSP90 family (DMAG-N-OXIDE), the favourable safety/toxicity profile as well as the promising preliminary results makes anti-HSP90 agents a new promising area in the oncology field.

The phase I study by Modi et al. [65] was done in advanced solid tumors. However, the majority of the patients enrolled on that trial were HER2 positive breast cancer patients and all responses were noted in this subset [65]. This led to the phase II trial of tanespimycin combined with trastuzumab in this patient population.

These results are in accordance with the one published by the same study group in the same study population, in a phase II trial [66]. The overall response rate was $22 \%$, the clinical benefit rate [complete response + partial response + stable disease] was $59 \%$, the median progression-free survival was 6 months (95\% CI: 4-9), and the median overall survival was 17 months (95\% CI: 16-28) [66].

Currently 17-AAG and 17-DMAG are not under clinical development but there are many other Hsp90 inhibitors (retaspimycin HCL, NVP-AUY922, NVP-BEP800, CNF2024/BIIB021, SNX-5422, STA-9090 etc.) with better pharmacological and toxicological properties that are currently under investigation, holding great promise in breast cancer treatment [67-73]. More specifically, retaspimycin HCL (IPI-504) has shown promising results with a safe toxicity profile and antitumor activity in a phase I trial in patients with relapsed or relapsed and refractory multiple myeloma [74], but it has shown modest results in a phase II trial in patients with castration-resistant prostate cancer; it would be tempting to see its activity in breast cancer patients [75].

Novel synthetic Hsp90 inhibitors based on diverse chemical scaffolds have been developed; it seems that they generally have an improved pharmacologic profile when compared to 17-AAG, especially with regard to their availability through synthesis, evasion of multidrug resistance (MDR)-mediated efflux, metabolic stability, water solubility and ease of administration, and retained biological activity over a wider panel of tumors [70,71]. The first synthetic Hsp90 inhibitor to enter clinic is CNF2024/BIIB021 [70]. There are currently several ongoing Phase I trial studies of oral CNF2024/BIIB021 in advanced solid tumors. As far as breast cancer is concerned CNF2024/BIIB021 is currently under evaluation alone or in combination with trastuzumab [76]. A second synthetic Hsp90 
inhibitor to enter clinic is VER-52296/NVP-AUY922 [73]. A Phase I-II trial of intravenously administered AUY922 is currently open, with the Phase I portion of the trial recruiting patients with several types of cancer, whilst the Phase II portion is limited to patients with either HER2 positive or ER positive locally advanced or metastatic breast cancer [76].

Another active small-molecule Hsp90 inhibitor based on the 6,7-dihydroindazol-4-one scaffold is SNX-5422 [77]. SNX-5422 has been evaluated in a phase I trial in patients with refractory solid malignancies and lymphomas. In this study, no objective responses were observed, but long-lasting stabilizations were obtained. Although no clinically significant drug-related ocular toxicity was seen in this study, the development of SNX-5422 has been discontinued because of ocular toxicity seen in animal models and in a separate phase I study. Finally, STA-9090, is claimed to have a chemical structure unrelated to the ansamycin family of Hsp90 inhibitors, such as 17-AAG. This agent is currently enrolling patients in two dose-ranging phase I clinical trials in solid tumors [76]. Therefore, it seems that further research exploring this therapeutic interaction and the activity of HSP90 inhibitors is clearly warranted.

\section{Hsp90 Biology and HSP90 Inhibitors in the Different Subtypes of Breast Cancer}

As is the case with many other targeted agents, patient selection seems to be the major limitation to the success of HSP90 inhibitors. In this section Hsp90 biology as well as the implications of HSP90 inhibitors in the different subtypes of breast cancer are discussed.

Concerning HER2 positive breast cancer, it is known that HSP90 is required for the stabilization of essential components of EGFR and HER2 signaling (HER2, AKT, c-SRC, RAF and HIF-1 $\alpha$ ). HER2 is among the most sensitive client proteins of HSP90 [78,79], and HSP90 inhibition mediates degradation of HER2, as well as PI3K and AKT in HER2-overexpressing cancer cells [80]. Consequently, HSP90 inhibitors plus trastuzumab have significant anticancer activity in patients with HER2-positive, metastatic breast cancer previously progressing on trastuzumab [66]. This is in line with the preclinical studies that demonstrated that HER2 is one of the most sensitive client proteins of HSP90 inhibition, given that HSP90 is a crucial facilitator of oncogene addiction [81]. Moreover, important to note is that the phase II study of tanespimycin and trastuzumab did not evaluate pre-treatment HSP90 expression in tumor tissues from breast cancer patients [66]. Although a number of agents are in development for HER2 positive and ER-positive breast cancers, HSP90 inhibitors also represent therapeutic opportunities in other molecular subtypes.

Triple negative breast cancer (TNBC) is defined by the lack of expression of ER, PR and HER2 receptors and has a higher rate of distant recurrence and a poorer prognosis than other breast cancer subtypes. Unfortunately, the lack of expression of a credentialed therapeutic target in this subtype of breast cancer limits the effective treatment options. In pre-clinical models, TNBCs have been sensitive to Hsp90 inhibitors [82,83]. Similarly to HER2 positive tumors, TNBCs were sensitive to Hsp90 inhibition through down-regulation of components of the Ras/Raf/MARK pathway in preclinical and in vitro studies [83]. Being a central integrator of multiple pathways, activation of HSP90 may maintain the malignant phenotype, facilitate metastasis, and promote treatment-resistance under the stress of cancer therapy in multiple breast cancer subtypes. It has been suggested that Hsp90 up-regulation may be a sign of poor disease prognosis [47] and a recent study has demonstrated that 
co-expression of HSP90 and PI3K or expression of HSP90 in combination with the loss of PTEN were associated with significantly worse recurrence-free survival in patients with breast cancer [84].

Finally, HSP90 inhibitors may have a central role in ER-positive breast cancer tumors. It is known that aromatase inhibitor-resistant breast cancers do not rely on hormone-mediated signaling, but growth factor signaling is important for their growth. It has been found that the ER $\alpha$ can be phosphorylated and activated in a ligand-independent manner. This activation is mainly due to the cross-talk between the ER $\alpha$ and growth factor signaling pathways, such as insulin-like growth factor-I receptor and HER2-mediated signaling pathways. These growth factor signaling proteins are important for resistance to aromatase inhibitors and are also HSP90 client proteins [85]. Interestingly, Wong et al. [84] provided data to support the notion that HSP90 inhibitors may be an effective therapy to treat aromatase inhibitor-resistant breast cancers and that improved efficacy can be achieved by combined use of a HSP90 inhibitor and an AKT inhibitor.

\section{Conclusions}

In conclusion, it could be said that Hsp90 plays a key role in breast carcinogenesis. It forms several discrete complexes, each containing distinct groups of co-chaperones that assist protein folding and refolding during stress, protein transport and degradation. It interacts with a variety of proteins ER, tumor suppressor p53 protein, angiogenesis transcription factor HIF-1alpha, antiapoptotic kinase Akt, Raf-1 MAP kinase and a variety of receptor tyrosine kinases of the erbB family. Hsp90 overexpression has been proposed as a component of a mechanism through which breast cancer cells become resistant to various stress stimuli. Given the above observation, it would appear that pharmacological inhibition of HSPs can provide therapeutic opportunities in the field of cancer treatment. HSP90 inhibitors have been hypothesized to be active preclinically in a wide variety of tumor types but clinically have shown objective tumor responses in HER2 positive breast cancer and most recently in ALK+ lung cancer. Sensitive client proteins such as HER2 are very important. Finally it should be noted that prospective studies are needed to evaluate the role of HSP90 expression as a prognostic and predictive marker of response to HSp90 inhibition from pre-treatment tumor samples.

\section{Acknowledgements}

F.Z. is receiving a research grant from HeSMO.

\section{Conflict of Interest}

The authors have declared no conflicts of interest.

\section{References}

1. Lindquist, S.; Craig, E.A. The heat shock proteins. Ann. Rev. Genet. 1988, 22, 631-637.

2. Bukau, B.; Weissman, J.; Horwich, A. Molecular chaperones and protein quality control. Cell 2006, 125, 443-451.

3. Calderwood, S.K.; Ciocca, D.R. Heat shock proteins: Stress proteins with Janus-like properties in cancer. Int. J. Hyperther. 2008, 24, 31-39. 
4. Tang, D.; Khaleque, M.A.; Jones, E.L.; Theriault, J.R.; Li, C.; Wong, W.H.; Stevenson, M.A.; Calderwood, S.K. Expression of heat shock proteins and heat shock protein messenger ribonucleic acid in human prostate carcinoma in vitro and in tumors in vivo. Cell Stress Chaperones 2005, 10, 46-58.

5. Jones, E.L.; Zhao, M.J.; Stevenson, M.A.; Calderwood, S.K. The 70 kilodalton heat shock protein is an inhibitor of apoptosis in prostate cancer. Int. J. Hyperther. 2004, 20, 835-849.

6. Gabai, V.L.; Meriin, A.B.; Yaglom, J.A.; Volloch, V.Z.; Sherman, M.Y. Role of Hsp70 in regulation of stress-kinase JNK: Implications in apoptosis and aging. FEBS Lett. 1998, 438, 1-4.

7. Garrido, C.; Brunet, M.; Didelot, C.; Zermati, Y.; Schmitt, E.; Kroemer, G. Heat shock proteins 27 and 70: Anti-apoptotic proteins with tumorigenic properties. Cell Cycle 2006, 5, 2592-2601.

8. Calderwood, S.K. Heat shock proteins in breast cancer progression-A suitable case for treatment? Int. J. Hyperther. 2010, 26, 681-685.

9. Sorger, P.K.; Pelham, H.R.B. Yeast heat shock factor is an essential DNA-binding protein that exhibits temperature-dependent phosphorylation. Cell 1988, 54, 855-864.

10. Wu, C. Heat shock transcription factors: Structure and regulation. Ann. Rev. Cell Dev. Biol. 1995, 11, 441-469

11. Khaleque, M.A.; Bharti, A.; Sawyer, D.; Gong, J.; Benjamin, I.J.; Stevenson, M.A.; Calderwood, S.K. Induction of heat shock proteins by heregulin betal leads to protection from apoptosis and anchorage-independent growth. Oncogene 2005, 24, 6564-6573.

12. Khaleque, M.A.; Bharti, A.; Gong, J.; Gray, P.J.; Sachdev, V.; Ciocca, D.R.; Stati, A.; Fanelli, M.; Calderwood, S.K. Heat shock factor 1 represses estrogen-dependent transcription through association with MTA1. Oncogene 2008, 27, 1886-1893.

13. Wang, Y.; Theriault, J.R.; He, H.; Gong, J.; Calderwood, S.K. Expression of a dominant negative heat shock factor-1 construct inhibits aneuploidy in prostate carcinoma cells. J. Biol. Chem. 2004, 279, 32651-32659.

14. Dai, C.; Whitesell, L.; Rogers, A.B.; Lindquist, S. Heat shock factor 1 is a powerful multifaceted modifier of carcinogenisis. Cell 2007, 130, 1005-1018.

15. Leav, I.; Plescia, J.; Goel, H.L.; Li, J.; Jiang, Z.; Cohen, R.J.; Languino, L.R.; Altieri, D.C. Cytoprotective mitochondrial chaperone TRAP-1 as a novel molecular target in localized and metastatic prostate cancer. Am. J. Pathol. 2010, 176, 393-401.

16. Wadhwa, R.; Taira, K.; Kaul, S.C. An Hsp70 family chaperone, mortalin/mthsp70/PBP74/Grp75: What, when, and where? Cell Stress Chaperones 2002, 7, 309-316.

17. Lai, B.T.; Chin, N.W.; Stanek, A.E.; Keh, W.; Lanks, K.W. Quantitation and intracellular localization of the $85 \mathrm{~K}$ heat shock protein by using monoclonal and polyclonal antibodies. Mol. Cell. Biol. 1984, 4, 2802-2810.

18. Whitley, D.; Goldberg, S.P.; Jordan, W.D. Heat shock proteins: A review of the molecular chaperones. J. Vasc. Surg. 1999, 29, 748-751.

19. Beliakoff, J.; Whitesell, L. Hsp90: An emerging target for breast cancer therapy. Anticancer Drugs 2004, 15, 651-662.

20. Chen, B.; Zhong, D.; Monteiro, A. Comparative genomics and evolution of the HSP90 family of genes across all kingdoms of organisms. BMC Genomics 2006, 7, 156. 
21. Chen, B.; Piel, W.H.; Gui, L.; Bruford, E.; Monteiro, A. The Hsp90 family of genes in the human genome: Insights into their divergence and evolution. Genomics 2005, 86, 627-637.

22. Grammatikakis, N.; Vultur, A.; Ramana, C.V.; Siganou, A.; Schweinfest, C.W.; Watson, D.K.; Raptis, L. The role of Hsp90N, a new member of the Hsp90 family, in signal transduction and neoplastic transformation. J. Biol. Chem. 2002, 277, 8312-8320.

23. Zurawska, A.; Urbanski, J.; Bieganowski, P. Hsp90n-An accidental product of a fortuitous chromosomal translocation rather than a regular Hsp90 family member of human proteome. Biochim. Biophys. Acta 2008, 1784, 1844-1846.

24. Pearl, L.H.; Prodromou, C. Structure and in vivo function of Hsp90. Curr. Opin. Struct. Biol. 2000, 10, 46-51.

25. Prodromou, C.; Pearl, L.H. Structure and functional relationships of Hsp90. Curr. Cancer Drug Targets 2003, 3, 301-323.

26. Pearl, L.H.; Prodromou, C. Structure, function, and mechanism of the Hsp90 molecular chaperone. Adv. Protein Chem. 2001, 59, 157-186.

27. Stebbins, C.E.; Russo, A.A.; Schneider, C.; Rosen, N.; Hartl, F.U.; Pavletich, N.P. Crystal structure of an Hsp90-geldanamycin complex: Targeting of a protein chaperone by an antitumor agent. Cell 1997, 89, 239-250.

28. Prodromou, C.; Roe, S.M.; O’Brien, R.; Ladbury, J.E.; Piper, P.W.; Pearl, L.H. Identification and structural characterization of the ATP/ADP-binding site in the Hsp90 molecular chaperone. Cell 1997, 90, 65-75.

29. Prodromou, C.; Roe, S.M.; Piper, P.W.; Pearl, L.H. A molecular clamp in the crystal structure of the $N$-terminal domain of the yeast Hsp90 chaperone. Nat. Struct. Biol. 1997, 4, 477-482.

30. Meyer, P.; Prodromou, C.; Hu, B.; Vaughan, C.; Roe, S.M.; Panaretou, B.; Piper, P.W.; Pearl, L.H. Structural and functional analysis of the middle segment of Hsp90: Implications for ATP hydrolysis and client protein and cochaperone interactions. Mol. Cell 2003, 11, 647-658.

31. Shiau, A.K.; Harris, S.F.; Southworth, D.R.; Agard, D.A. Structural Analysis of E. coli hsp90 reveals dramatic nucleotide-dependent conformational rearrangements. Cell 2006, 127, 329-340.

32. Ali, M.M.; Roe, S.M.; Vaughan, C.K.; Meyer, P.; Panaretou, B.; Piper, P.W.; Prodromou, C.; Pearl, L.H. Crystal structure of an Hsp90-nucleotide-p23/Sba1 closed chaperone complex. Nature 2006, 440, 1013-1017.

33. Dollins, D.E.; Warren, J.J.; Immormino, R.M.; Gewirth, D.T. Structures of GRP94-nucleotide complexes reveal mechanistic differences between the hsp90 chaperones. Mol. Cell 2007, 28, 41-56.

34. Wandinger, S.K.; Richter, K.; Buchner, J. The Hsp90 chaperone machinery. J. Biol. Chem. 2008, 283, 18473-18477.

35. Den, R.B.; Lu, B. Heat shock protein 90 inhibition: rationale and clinical potential. Ther. Adv. Med. Oncol. 2012, 4, 211-218.

36. Pearl, L.H.; Prodromou, C.; Workman, P. The Hsp90 molecular chaperone: An open and shut case for treatment. Biochem. J. 2008, 410, 439-453.

37. Jhaveri, K.; Taldone, T.; Modi, S.; Chiosis, G. Advances in the clinical development of heat shock protein 90 (Hsp90) inhibitors in cancers. Biochim. Biophys. Acta 2012, 1823, 742-755. 
38. Radanyi, C.; Le Bras, G.; Messaoudi, S.; Bouclier, C.; Peyrat, J.F.; Brion, J.D.; Marsaud, V.; Renoir, J.M.; Alami, M. Synthesis and biological activity of simplified denoviose-coumarins related to novobiocin as potent inhibitors of heat-shock protein 90 (Hsp90). Bioorg. Med. Chem. Lett. 2008, 18, 2495-2498.

39. Zhang, T.; Hamza, A.; Cao, X.; Wang, B.; Yu, S.; Zhan, C.G.; Sun, D. A novel Hsp90 inhibitor to disrupt Hsp90/CDC37 complex against pancreatic cancer cells. Mol. Cancer Ther. 2008, 7, 162-170.

40. Holmes, J.L.; Sharp, S.Y.; Hobbs, S.; Workman, P. Silencing of HSP90 cochaperone AHA1 expression decreases client protein activation and increases cellular sensitivity to the HSP90 inhibitor 17-allylamino-17-demethoxygeldanamycin. Cancer Res. 2008, 68, 1188-1197.

41. Hadchity, E.; Aloy, M.T.; Paulin, C.; Armandy, E.; Watkin, E.; Rousson, R.; Gleave, M.; Chapet, O.; Rodriguez-Lafrasse, C. Heat shock protein 27 as a new therapeutic target for radiation sensitization of head and neck squamous cell carcinoma. Mol. Ther. 2009, 17, 1387-1394.

42. Powers, M.V.; Workman, P. Inhibitors of the heat shock response: Biology and pharmacology. FEBS Lett. 2007, 581, 3758-3769.

43. Banerji, U. Heat shock protein 90 as a drug target: Some like it hot. Clin Cancer Res. 2009, 15, 9-14.

44. Conroy, S.E.; Latchman, D.S. Do heat shock proteins have a role in breast cancer? Br. J. Cancer 1996, 74, 717-721.

45. Yano, M.; Naito, Z.; Tanaka, S.; Asano, G. Expression and roles of heat shock proteins in human breast cancer. Jpn. J. Cancer Res. 1996, 87, 908-915.

46. Yano, M.; Naito, Z.; Yokoyama, M.; Shiraki, Y.; Ishiwata, T.; Inokuchi, M.; Asano, G. Expression of hsp90 and cyclin D1 in human breast cancer. Cancer Lett. 1999, 137, 45-51.

47. Pick, E.; Kluger, Y.; Giltnane, J.M.; Moeder, C.; Camp, R.L.; Rimm, D.L.; Kluger, H.M. High HSP90 expression is associated with decreased survival in breast cancer. Cancer Res. 2007, 67, 2932-2937.

48. Zagouri, F.; Sergentanis, T.N.; Nonni, A.; Papadimitriou, C.A.; Michalopoulos, N.V.; Domeyer, P.; Theodoropoulos, G.; Lazaris, A.; Patsouris, E.; Zogafos, E.; et al. Hsp90 in the continuum of breast ductal carcinogenesis: Evaluation in precursors, preinvasive and ductal carcinoma lesions. BMC Cancer 2010, 10, 353.

49. Zagouri, F.; Sergentanis, T.; Nonni, A.; Papadimitriou, C.; Pazaiti, A.; Michalopoulos, N.; Safioleas, P.; Lazaris, A.; Theodoropoulos, G.; Patsouris, E.; et al. Decreased Hsp90 expression in infiltrative lobular carcinoma: An immunohistochemical study. BMC Cancer 2010, 10, 409.

50. Zagouri, F.; Nonni, A.; Sergentanis, T.N.; Papadimitriou, C.A.; Michalopoulos, N.V.; Lazaris, A.C.; Patsouris, E.; Zografos, G.C. Heat shock protein90 in lobular neoplasia of the breast. BMC Cancer 2008, 8, 312.

51. Kim, L.S.; Lee, H.S.; Choi, J.W.; Kang, H.J.; Price, J.E. The role of heat shock protein 90/70 as potential molecular therapeutic targets in breast cancer. Proc. Am. Assoc. Cancer Res. 2005, 46, Abstract 2346.

52. O’Malley, F.P.; Peder, S.E. Invasive Carcinomas: Special Types in Breast Pathology; Elsevier: New York, NY, USA, 2006.

53. Sun, B.; Zhang, S.; Zhang, D. Identification of metastasis-related proteins and their clinical relevance to triple-negative human breast cancer. Clin. Cancer Res. 2008, 14, 7050-7059. 
54. Reis-Filho, J.S.; Tutt, A.N. Triple negative tumours: A critical review. Histopathology 2008, 52, 108-118.

55. Jhaveri, K.L.; Iyengar, N.M.; Corben, A.; Patil, S.; Akram, M.; Towers, R.; Sakr, R.; Hudis, C.; King, T.A.; Rosen, N.; et al. Biomarkers that predict sensitivity to heat shock protein 90 inhibitors (HSP90i). J. Clin. Oncol. 2012, 30, Abstract 10618.

56. Zagouri, F.; Sergentanis, T.N.; Provatopoulou, X.; Kalogera, E.; Chrysikos, D.; Lymperi, M.; Papadimitriou, C.A.; Zografos, E.; Bletsa, G.; Kalles, V.S.; et al. Serum levels of HSP90 in the continuum of breast ductal and lobular lesions. In Vivo 2011, 25, 669-672.

57. Munster, P.N.; Basso, A.; Solit, D.; Norton, L.; Rosen, N. Modulation of Hsp90 function by ansamycins sensitizes breast cancer cells to chemotherapy-induced apoptosis in an RB- and schedule-dependent manner. Clin. Cancer Res. 2001, 7, 2228-2236.

58. Bagatell, R.; Khan, O.; Paine-Murrieta, G.; Taylor, C.W.; Akinaga, S.; Whitesell, L. Destabilization of steroid receptors by heat shock protein 90-binding drugs: A ligand-independent approach to hormonal therapy of breast cancer. Clin. Cancer Res. 2001, 7, 2076-2084.

59. Xing, H.; Weng, D.; Chen, G.; Tao, W.; Zhu, T.; Yang, X.; Meng, L.; Wang, S.; Lu, Y.; Ma, D. Activation of fibronectin/PI-3K/Akt2 leads to chemoresistance to docetaxel by regulating survivin protein expression in ovarian and breast cancer cells. Cancer Lett. 2008, 261, 108-119.

60. Eccles, S.A.; Massey, A.; Raynaud, F.I.; Sharp, S.Y.; Box, G.; Valenti, M.; Patterson, L.; de Haven Brandon, A.; Gowan, S.; Boxall, F.; et al. NVP-AUY922: A novel heat shock protein 90 inhibitor active against xenograft tumor growth, angiogenesis, and metastasis. Cancer Res. 2008, 68, 2850-2860.

61. Porter, J.R.; Fritz, C.C.; Depew, K.M. Discovery and development of Hsp90 inhibitors: A promising pathway for cancer therapy. Curr. Opin. Chem. Biol. 2010, 14, 412-420.

62. Kim, Y.S.; Alarcon, S.V.; Lee, S.; Lee, M.J.; Giaccone, G.; Neckers, L.; Trepel, J.B. Update on Hsp90 inhibitors in clinical trial. Curr. Top Med. Chem. 2009, 9, 1479-1492.

63. Hadden, M.K.; Lubbers, D.J.; Blagg, B.S. Geldanamycin, radicicol, and chimeric inhibitors of the Hsp90 N-terminal ATP binding site. Curr. Top Med. Chem. 2006, 6, 1173-1182.

64. Clarke, P.A.; Hostein, I.; Banerji, U.; Stefano, F.D.; Maloney, A.; Walton, M.; Judson, I.; Workman, P. Gene expression profiling of human colon cancer cells following inhibition of signal transduction by 17-allylamino-17-demethoxygeldanamycin, an inhibitor of the hsp90 molecular chaperone. Oncogene 2000, 19, 4125-4133.

65. Modi, S.; Stopeck, A.T.; Gordon, M.S.; Mendelson, D.; Solit, D.B.; Bagatell, R.; Ma, W.; Wheler, J.; Rosen, N.; Norton, L.; et al. Combination of trastuzumab and tanespimycin (17-AAG, KOS-953) is safe and active in trastuzumab-refractory HER-2 overexpressingbr east cancer: A phase I doseescalation study. J. Clin. Oncol. 2007, 25, 5410-5417.

66. Modi, S.; Stopeck, A.; Linden, H.; Solit, D.; Chandarlapaty, S.; Rosen, N.; D’Andrea, G.; Dickler, M.; Moynahan, M.E.; Sugarman, S.; et al. HSP90 inhibition is effective in breast cancer: A phase II trial of tanespimycin (17-AAG) plus trastuzumab in patients with HER2-positive metastatic breast cancer progressing on trastuzumab. Clin. Cancer Res. 2011, 17, 5132-5139.

67. Taldone, T.; Gozman, A.; Maharaj, R.; Chiosis, G. Targeting Hsp90: Small-molecule inhibitors and their clinical development. Curr. Opin. Pharmacol. 2008, 8, 370-374. 
68. Stingl, L.; Stühmer, T.; Chatterjee, M.; Jensen, M.R.; Flentje, M.; Djuzenova, C.S. Novel HSP90 inhibitors, NVP-AUY922 and NVP-BEP800, radiosensitise tumour cells through cell-cycle impairment, increased DNA damage and repair protraction. Br. J. Cancer 2010, 102, 1578-1591.

69. Jensen, M.R.; Schoepfer, J.; Radimerski, T.; Massey, A.; Guy, C.T.; Brueggen, J.; Quadt, C.; Buckler, A.; Cozens, R.; Drysdale, M.J.; et al. NVP-AUY922: A small molecule HSP90 inhibitor with potent antitumor activity in preclinical breast cancer models. Breast Cancer Res. 2008, 10, R33.

70. Chiosis, G.; Kang, Y.; Sun, W. Discovery and development of purine-scaffold Hsp90 inhibitors. Expert Opin. Drug Discov. 2008, 3, 99-114.

71. McDonald, E.; Jones, K.; Brough, P.A.; Drysdale, M.J.; Workman, P. Discovery and development of pyrazole-scaffold Hsp90 inhibitors. Curr. Top Med. Chem. 2006, 6, 1193-1203.

72. Elfiky, A.; Saif, M.W.; Beeram, M.; O’Brien, S.; Lammanna, N.; Castro, J.E.; Woodworth, J.; Perea, R.; Storgard, C.; von Hoff, D.D. BIIB021, an oral, synthetic non-ansamycin Hsp90 inhibitor: Phase I experience. J. Clin. Oncol. 2008, 26 (Suppl.), Abstract 2503.

73. Eccles, S.A.; Massey, A.; Raynaud, F.I.; Sharp, S.Y.; Box, G.; Valenti, M.; Patterson, L.; de Haven Brandon, A.; Gowan, S.; Boxall, F.; et al. NVPAUY922: A novel heat shock protein 90 inhibitor active against xenograft tumor growth, angiogenesis, and metastasis. Cancer Res. 2008, $68,2850-2860$.

74. Siegel, D.; Jagannath, S.; Vesole, D.H.; Borello, I.; Mazumder, A.; Mitsiades, C.; Goddard, J.; Dunbar, J.; Normant, E.; Adams, J.; et al. A phase 1 study of IPI-504 (retaspimycin hydrochloride) in patients with relapsed or relapsed and refractory multiple myeloma. Leuk. Lymphoma 2011, 52, 2308-2315.

75. Oh, W.K.; Galsky, M.D.; Stadler, W.M.; Srinivas, S.; Chu, F.; Bubley, G.; Goddard, J.; Dunbar, J.; Ross, R.W. Multicenter phase II trial of the heat shock protein 90 inhibitor, retaspimycin hydrochloride (IPI-504), in patients with castration-resistant prostate cancer. Urology 2011, 78, 626-630.

76. ClinicalTrials.gov. Available online: http://www.clinicaltrials.gov/ (accessed on 30 August 2012).

77. Hall, S.E. Discovery and pre-clinical profile of SNX-5422: An orally active Hsp90 inhibitor in phase 1 trials for solid and hematological tumors. In Proceedings of the 99th Annual Meeting of the American Association for Cancer Research, San Diego, CA, USA, 11-15 April 2008; Abstract 2449.

78. Basso, A.D.; Solit, D.B.; Munster, P.N.; Rosen, N. Ansamycin antibiotics inhibit Akt activation and cyclin D expression in breast cancer cells that overexpress HER2. Oncogene 2002, 21, 1159-1166.

79. Xu, W.; Mimnaugh, E.; Rosser, M.F.; Nicchitta, C.; Marcu, M.; Yarden, Y.; Neckers, L. Sensitivity of mature Erbb2 to geldanamycin is conferred by its kinase domain and is mediated by the chaperone protein Hsp90. J. Biol. Chem. 2001, 276, 3702-3708.

80. Workman, P.; Burrows, F.; Neckers, L.; Rosen, N. Drugging the cancer chaperone HSP90: Combinatorial therapeutic exploitation of oncogene addiction and tumor stress. Ann. NY Acad. Sci. 2007, 1113, 202-216.

81. Trepel, J.; Mollapour, M.; Giaccone, G.; Neckers, L. Targeting the dynamic HSP90 complex in cancer. Nat. Rev. Cancer 2010, 10, 537-549. 
82. Mehta, P.P.; Whalen, P.; Baxi, S.M.; Kung, P.P.; Yamazaki, S.; Yin, M.J. Effective targeting of triple-negative breast cancer cells by PF-4942847, a novel oral inhibitor of Hsp 90. Clin. Cancer Res. 2011, 17, 5432-5442.

83. Caldas-Lopes, E.; Cerchietti, L.; Ahn, J.H.; Clement, C.C.; Robles, A.I.; Rodina, A.; Moulick, K.; Taldone, T.; Gozman, A.; Guo, Y.; et al. Hsp90 inhibitor PU-H71, a multimodal inhibitor of malignancy, induces complete responses in triple-negative breast cancer models. Proc. Natl. Acad. Sci. USA 2009, 106, 8368-8373.

84. Song, C.H.; Park, S.Y.; Eom, K.Y.; Kim, J.H.; Kim, S.W.; Kim, J.S.; Kim, I.A. Potential prognostic value of heat-shock protein 90 in the presence of phosphatidylinositol-3-kinase overexpression or loss of PTEN, in invasive breast cancers. Breast Cancer Res. 2010, 12, R20.

85. Wong, C.; Chen, S. Heat shock protein 90 inhibitors: New mode of therapy to overcome endocrine resistance. Cancer Res. 2009, 69, 8670-8677.

(C) 2012 by the authors; licensee MDPI, Basel, Switzerland. This article is an open access article distributed under the terms and conditions of the Creative Commons Attribution license (http://creativecommons.org/licenses/by/3.0/). 